\title{
耐火材料发展概述
}

\author{
李红霞 \\ (中钢集团洛阳耐火材料研究院有限公司 先进耐火材料国家重点实验室，洛阳 471039)
}

摘 要: 本文简要介绍了中国耐火材料现状, 结合高温工业技术发展需求, 阐述了耐火材料的发展态势和发展方 向。指出结构功能一体化设计与制备是以长寿化、功能化、轻量化、智能化、绿色化为特征的先进耐火材料发展 的核心。结合新型高效隔热耐火材料、钢铁冶金连铸用先进功能耐火材料的研究, 介绍了先进耐火材料的组成-结 构-性能一功能一体化设计理念与制备技术, 采用有限元数值模拟、融合先进陶瓷技术及梯度多层复合设计, 实现了 关键服役性能的最优化设计与制备。

关 键 词：先进耐火材料; 结构功能一体化设计; 隔热耐火材料; 功能耐火材料; 综述 中图分类号: TQ175 文献标识码: A

\section{Development Overview of Refractory Materials}

\author{
LI Hong-Xia
}

(Sinosteel Luoyang Institute of Refractories Research Co., Ltd., State Key Lab of Advanced Refractories, Luoyang 471039, China)

\begin{abstract}
In this paper, current situation of refractory industry in China is introduced briefly. Developing tendency of refractory materials is remarked based on the technical development of high temperature industries. Advanced refractory materials, characterized by long service life, functionalization, lightweight and ecological-friendly design, play very important roles in sustainable development of high temperature industries. Since the key service properties of advanced refractories constrain each other in traditional material design and fabrication, new design methods are developed to optimize the key service properties simultaneously. Combined with the development of new insulating materials, and functional refractories used in steel-making industry, structure-function combining design concept and new fabrication technologies are introduced by applying FEM analysis, bridging of advance ceramic technologies, and multilayered/gradient composite structure.
\end{abstract}

Key words: advanced refractories; structure-function combining design; insulating materials; functional refractories; review

\section{1 中国耐火材料行业的现状}

耐火材料应用于钢铁、有色、建材、化工、电 力、环保、航天等领域的高温过程，是所有高温工 业新工艺和新技术实施的重要基础和支撑材料，对
高温工业产品质量提升与品种开发、高效生产和节 能减排具有重要作用。钢铁、有色和石化等高温行 业的高速发展，关键装备和技术的进步，极大地带 动了我国耐火材料的科技创新和产业发展。我国已 成为全球耐火材料和耐火原料生产、消费和出口最

收稿日期: 2016-07-30; 收到修改稿日期：2016-12-05

基金项目：国家自然科学基金河南联合基金重点项目(U1604252); 国家自然科学基金(51372231, 51772277) Key Program for Henan Joint Funds of the National Natural Science Foundation of China (U1604252); National Natural Science Foundation of China (51372231, 51772277)

作者简介：李红霞(1965-)，女，博士，教授级高级工程师. E-mail: lihongx0622@126.com 
多的国家，在国际耐火材料领域占有重要地位。 $\mathrm{Al}_{2} \mathrm{O}_{3}-\mathrm{SiO}_{2}$ 质、富镁碱性制品、碳化硅基复合材料、 含碳材料构成出口优势 ${ }^{[1]}$; 洁净钢精炼用系列碱性 材料 ${ }^{[2] 、}$ 精炼和高效连铸用低碳或无碳功能材料的设 计与制备 ${ }^{[3-7]}$ 、热风炉等用低蠕变 $\mathrm{Al}_{2} \mathrm{O}_{3}-\mathrm{SiO}_{2}$ 材料 ${ }^{[8]}$ 、 干熄焦炉用复合氮化物结合碳化硅材料 ${ }^{[9]}$ 等关键材

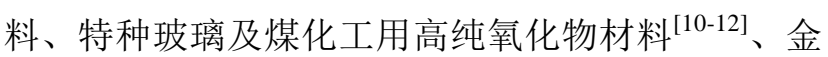
属冶炼用非氧化物材料 ${ }^{[1]}$ 等方面技术达到国际先进 或领先水平。在水泥窑、 RH 精炼装备上, 无铬材料 已成功取代含铬耐火材料 ${ }^{[12-14]}$ 。此外, 还开发出微 孔、微纳孔结构的系列新型高效隔热耐火材料 ${ }^{[15-16]}$ 。 2016 年, 全国耐火材料产量 2391.24 万吨, 占全球 产量 65\%以上; 耐火材料出口量 164.07 万吨, 耐火 材料原料出口量达到 356.35 万吨, 电熔镁砂、高铝 矾土、电熔刚玉、鳞片石墨等重要耐火原料对世界 耐火材料产业都有重要的支撑作用 ${ }^{[17]}$ 。

然而, 在直接关系到高温行业高效生产和能源 效率提升的先进耐火材料方面, 与国外先进水平相 比, 我国在品种、质量以及应用工程方面还有一些 差距 ${ }^{[18]}$ 。如陶瓷纤维主要以硅酸铝纤维及制品为主, 长期在 $1500^{\circ} \mathrm{C}$ 以上服役的高性能高纯氧化铝、氧化 锆纤维及其制品性能有一定差距; 生态环保生物可 降解纤维品种少, 使用温度低于 $1260^{\circ} \mathrm{C}$; 高效隔热 材料应用技术研究薄弱, 这些均制约着高温行业能 源效率的提升。在基础研究方面, 对耐火材料的高 温关键服役性能如高温热物理性能和热机械性能等 的研究和评价不足, 材料的高温服役行为与寿命预 测研究薄弱。

我国耐火原料资源承担着国内外双重消耗，目 前消耗速度已超过这些不可再生资源的承受限度, 优质矾土、优质石墨和优质镁矿资源已经显现紧

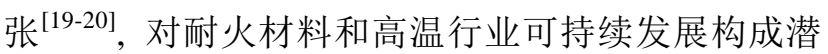
在威胁。尽管发展了低品位矿综合利用技术, 结构 均匀、性能优良的系列高铝均化料已形成一定的生 产规模, 但耐火材料的科学应用、资源综合利用以 及发展新的耐火原料体系仍然是关系耐火材料工业 可持续发展的紧迫任务。

\section{2 耐火材料的发展态势}

高温工业技术进步推动耐火材料产业的发展。 上世纪 70 年代全球能源危机以来, 为提升高温工业 节能降耗和生产效率, 发达国家高度重视耐火材料 及其应用技术研究, 以消耗 $70 \%$ 耐火材料的钢铁工 业为例, 吨钢耐火材料消耗从当时的 $30 \mathrm{~kg}$ 减少到本 世纪初的 $10 \mathrm{~kg}$ 左右, 日本已降至目前的 $7.1 \mathrm{~kg}$, 我
国在 10 18 kg ${ }^{[3]}$ 。上世纪 90 年代, 美国能源部支持 了多个耐火材料高温评价方法、纳米等新技术在耐 火材料中的应用研究等课题 ${ }^{[21]}$, 欧洲特别是德国、 英国不仅在耐火材料高温评价方法、标准、新材料 设计等方面给予支持, 为减少碳排放以及回归制造 业, 进一步强调了耐火材料在高温工业技术进 步、降低制造成本、节能减排和环境保护等方面的 作用。美国能源部在 2005 年发布了“Refractories for Industrial Processing: Opportunities for Improved Energy Effiency”, ${ }^{[21]}$ 报告, 2013 年美国橡树岭国家实验 室发表了 Improved Refractories=Energy Saving 的文 章 ${ }^{[22]}$, 美国 Missouri University of Science and Technology 的 Kent Peaslee 和美国 the Association of Iron and Steel Technology 前总裁 F. Kenneth Iverson 发 表的“Towards a “greener” Future with Advanced Refractories”, [23]，还有文献[24-25]均强调耐火材料对 节约能源和环保等方面的重要性。欧洲 2012 制定了 "Paving the way to 2050, the Ceramic Industry Roadmap,"[26], 着重强调了在节能和环保方面耐火 材料的独特作用以及对耐火材料发展的规划。英国 为提高高温制造业核心竞争力, 加大了对耐火材料 科技研发和教育培训的支持 ${ }^{[27]}$; 日本耐火材料工业 协会也在加大对耐火材料科技进步的支持, 并预测 日本耐火材料在未来将有较快增长 ${ }^{[28]}$ 。韩国目前从 事耐火材料相关研究的大学与以前相比已增加到 10 所以上。综上所述，随着高温制造业的技术进步， 耐火材料在性能和功能方面的提升空间较大, 具有 较大发展潜力。

当前我国钢铁、水泥、石化等高温行业产能过 剩, 发展面临日益严峻的全球性激烈竞争、能源资 源与环境约束。为提高全球核心竞争力和可持续发 展能力, 减少能源资源消耗, 高温行业将重点优化 产品结构、研究替代技术, 高端产品制造、高效生 产、绿色发展和智能制造是我国高温工业发展的方 向 ${ }^{[29-30]}$ 。为此而不断发展的新工艺、新技术使耐火 材料的服役环境更加苛刻, 对耐火材料的性能和服 役行为提出更高要求和挑战, 同时也更加凸显耐火 材料的技术突破在推动高温工业发展的基础性与战 略性功能。以长寿化、功能化、轻量化、智能化、 绿色化等为特征的先进耐火材料已成为耐火材料产 业的发展方向和研究热点。

耐火材料为多相跨尺度的非均质复合材料, 主 要由骨料、基质与气孔构成, 骨料与基质又由不同 的物相组成。高温下气固液交叉作用使耐火材料承 受着热、机械、化学等冲击和损耗, 耐火材料必须 满足不同服役环境对其高温热机械性能、热物理性 能、抗高温熔体渗透侵蚀、抗高温磨耗等不同性能 
的需要。耐火材料的高温服役失效一般表现为热震 破坏、侵蚀、结构损伤、功能劣化等, 对非氧化物 系材料还有氧化损伤。因此, 需要根据服役环境设 计材料, 加强从宏观到微观的结构设计、性能调控、 材料制备工艺和高温应用基础研究等方面的研究, 发展先进的材料设计与制备技术、注重应用技术研 究, 实现从组成与结构设计到服役性能与行为的调 控, 对推动长寿化、功能化、轻量化、部件化和绿 色化的先进耐火材料发展意义重大 ${ }^{[18,31-33] 。}$

先进耐火材料的发展需要融合治金、化学、计 算模拟等现代科学技术。重视材料服役过程行为和 失效机理研究; 以服役环境下热力学计算和高温模 拟为基础的材料组成精细化设计与调控 ${ }^{[34]}$; 基于服 役环境下温度场与应力场模拟、物理模拟和高温实验 模拟相结合, 进行材料结构设计和功能优化等 ${ }^{[5,35]}$, 提升了耐火材料的关键服役性能、功能和使用寿命。 强化与先进陶瓷、复合材料、表面/界面技术等学科 结合的跨学科研究, 发展新材料体系、先进制备技 术以及应用技术等 ${ }^{[33,36]}$, 从而发展出从纳米到毫米 的跨尺度材料复合设计、梯度结构复合、层状结构 复合、表面改性等功能化技术和先进耐火材料 ${ }^{[37-39]}$, 实现材料的高温力学性能、热物理性、功能性最优 化调控。

\section{3 先进耐火材料的研究进展}

发达国家高温工业革命性的新技术突破极大地 推动了新型功能及节能型耐火材料的研发, 如熔融 还原炼铁技术用关键耐火材料、薄带连铸用功能性 材料等的成功研发; 美国近年开发了具有隔热功能 又抗金属熔体、化学侵蚀性优良的多孔高性能材料, 促进了耐火材料功能化、减量化的发展 ${ }^{[21]}$; 美国、

日本、德国等开发了能长期在 $1500^{\circ} \mathrm{C}$ 以上使用的高 性能氧化铝、氧化锆纤维及其制品, 应用温度在 $1260^{\circ} \mathrm{C}$ 以上的环保生态可降解纤维 ${ }^{[40]}$, 德国近年来 加大了梯度结构与层状复合结构先进耐火材料的设 计与制备研究 ${ }^{[33]}$, 旨在实现高温工业节能并推动耐 火材料的功能化、轻量化和减量化发展。此外, 美 国、日本、欧盟等高度重视耐火原料, 将石墨列为 战略性材料, 并将美砂、矾土等 11 种原料列为潜在 战略性原材料, 因此在用后耐火材料的再资源化研 究和原料资源综合利用等方面开展了大量的工作, 日本用后耐火材料的资源化利用率已达 $60 \%$, 综合 利用率在 $90 \%$ 以上。

我国钢铁和十种有色金属产量均居全球第一, 耐火材料 70\%以上用于冶金工业, 深度参与治金过 程, 对其产品质量、生产效率和节能减排影响极大。
冶金工业转型升级, 产品高端化、效率提升和绿色 发展是其发展的战略任务, 迫切需要耐火材料服役 功能化和长寿化。由于高温下耐火材料与服役环境 间的高温反应与传热传质复杂, 要求耐火材料不能 污染金属熔体并具有特定功能。然而, 耐火材料关 键服役性能之间相互制约难以兼顾，局部苛刻服役 环境往往造成整体材料失效, 这已成为改善其服役 行为和功能的瓶颈。如何设计材料, 协同提升耐火 材料的关键服役性能, 现结合先进耐火材料国家重 点实验室的研究, 简要介绍对冶金流程能耗、生产 效率、以及钢的品种和质量具有重要影响的隔热材 料, 精炼和连铸用功能耐火材料的研发。

\section{1 高性能隔热材料的研究}

隔热材料是重要的高温工程材料, 不仅对钢铁 工业, 也对其他高温装置的隔热保温和能效提升有 重要意义。高性能隔热材料需要兼具高效隔热、轻 质高强、抗化学侵蚀等性能。

\subsection{1 耐高温超低导热复合材料的研发}

我国钢水过热度比国际先进水平高 $20^{\circ} \mathrm{C}$ 以上, 造成吨钢能耗高、钢中夹杂物多和耐火材料侵蚀严 重等问题。主要原因之一是钢水输运用铁水包、钢 包等用的隔热材料热导率高, 易粉化, 耐久性差。依 据材料传热机理, 采用多元复合-微结构调控的隔 热材料设计理念, 将二氧化硅气凝胶与具有纳米孔 结构的刚玉冶炼烟尘及陶瓷纤维复合, 提高了 $\mathrm{SiO}_{2}$ 气凝胶隔热材料的使用温度和力学性能 (见图 1)。通 过复合合理的遮光剂来减少高温近红外辐射传热, 进一步降低了材料的热导率。据此研发出在 $1100^{\circ} \mathrm{C}$ 服役的低成本、长寿命新型纳米隔热材料(见图 2)。

将该隔热材料与耐高温的氧化铝纤维进行复合, 研制出 $1600^{\circ} \mathrm{C}$ 以上长期使用的低热导率 $\left(1000^{\circ} \mathrm{C}\right.$ 为 $0.087 \mathrm{~W} \cdot \mathrm{m}^{-1} \cdot \mathrm{K}^{-1}$ ) 层状复合隔热材料(见表 1 )。该新 型隔热材料在钢包上应用显著提高其保温性能, 使 钢水过热度下降 $4^{\circ} \mathrm{C}$, 吨钢成本下降 1 1.4 元; 层状 复合隔热材料用于 $1800^{\circ} \mathrm{C}$ 窑炉节能 $20 \%$ 以上。

\subsection{2 非氧化物复合隔热材料的研发}

针对铝电解槽冰晶石的强侵蚀性气氛, 将氮化 硅-碳化硅复合材料的抗冰晶石侵蚀性能与多孔结 构材料的热阻性相结合, 复合高效遮光剂, 设计研 发出氮化硅/碳化硅复相多孔陶瓷隔热材料, 在提高 隔热保温性能的同时并具有良好的抗侵蚀性。采用 凝胶注模结合发泡法制备出多孔坏体, 固化干燥后 在氮气气氛下烧结, 制得具有多孔和纤维交织结构 的氮化硅一碳化硅复相多孔陶瓷。该材料气孔率和孔 结构可调控, 体积密度为 $0.45 \mathrm{~g} / \mathrm{cm}^{3}$ 的材料, 其耐压 强度为 $1.8 \mathrm{MPa}, 1000^{\circ} \mathrm{C}$ 时的热导率为 $0.22 \mathrm{~W} /(\mathrm{m} \cdot \mathrm{K})$ 。 

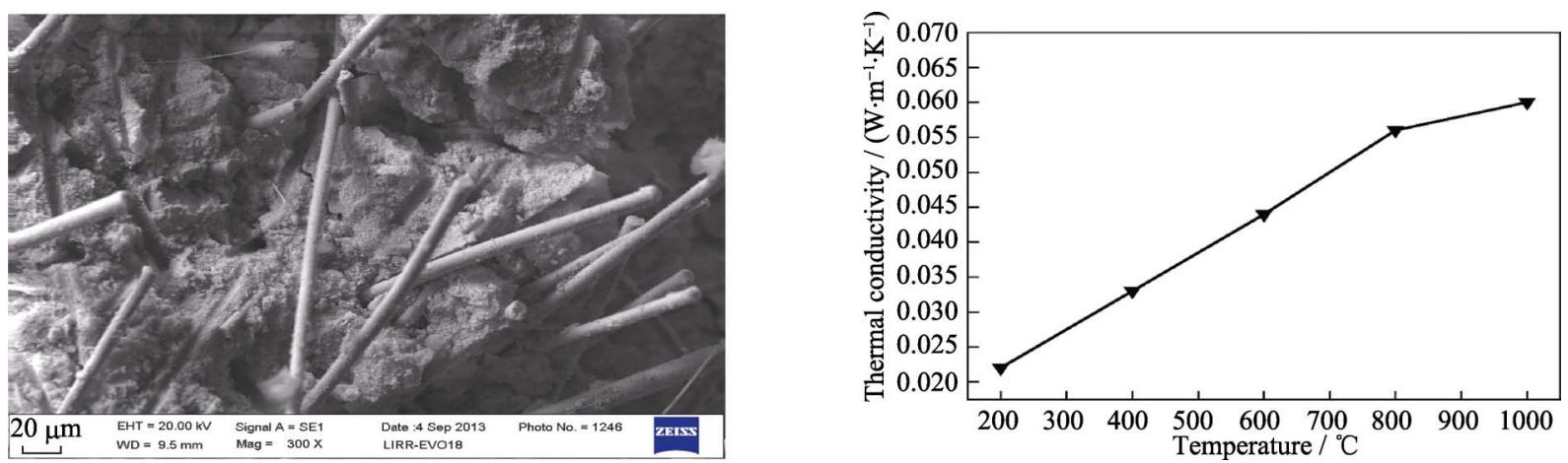

图 1 纤维增强二氧化硅一高温烟尘复合隔热材料的微结构及热导率随温度的变化 ${ }^{[41]}$

Fig. 1 Microstructure and effects of temperature on thermal conductivity of developed ceramic fiber enforced nano-SiO${ }_{2}$ - fumed-corundum insulation composite materials ${ }^{[41]}$

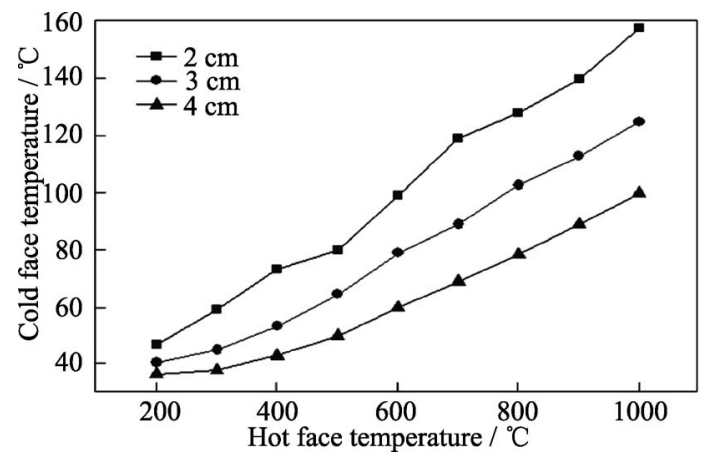

图 2 微纳米孔复合隔热材料的厚度与隔热效果 ${ }^{[41]}$

Fig. 2 Insulting effect versus the thickness of developed insulation composite materials with micro/nano-sized pores ${ }^{[41]}$

氮化硅/碳化硅复相多孔陶瓷隔热材料的显微结构 和产品照片如图 3 所示。

将硅酸铝纤维块、蛭石块、氮化硅/碳化硅复相 多孔陶瓷(STIC-n)置于密闭的石墨坩埚内, 并搁置 于冰晶石粉体上方, 在 $1000^{\circ} \mathrm{C}$ 条件下保温 $48 \mathrm{~h}$ 。图 4 为侵蚀试验前后各材料外观的对比。可以看到, 硅 酸铝纤维块、蛭石块均已严重侵蚀, 而 STIC-n 外观 变化不大, 侵蚀前后一维方向尺寸收缩约 $0.5 \%$, 质 量增加约 5\%, 显示了优良的抗含氟化物蒸气侵蚀 功能。

\section{2 连铸用梯度多层复合功能耐火材料的研究}

长水口、浸入式水口、塞棒等是支撑钢铁生产
的关键流程。连铸工艺高效运行的关键功能材料起 到控制钢液流量及分布、促进夹杂物上浮、防止钢 液氧化等重要作用, 其性能及服役行为对钢铁行业 提质增效、高品质钢材生产有重要影响 ${ }^{[3]}$ 。连铸用 耐火材料服役环境苛刻，经受钢液剧烈热冲击、高 通量钢液冲刷及高温熔渣与钢液的动态侵蚀。长水 口等功能耐火材料一般由碳含量在 $15 \%$ 30\%(w) 的氧化物一碳复合材料制备而成, 较高的碳含量对 提高材料的抗热震性和抗熔渣侵蚀性有利, 但对高 品质钢易产生碳污染并易引起非金属夹杂物, 且材 料抗氧化、抗钢液侵蚀性差。为保证高品质钢生产, 连铸用耐火材料的发展方向是低碳或无碳的氧化物 一碳复合材料, 为此, 需要协同提升优化其抗侵蚀 与抗热震性等关键服役性能。

氧化物一碳复合耐火材料中的碳来源于石墨和 作为结合相的酚醛树脂裂解产生的非晶态碳等。不 同碳源及其分布对材料服役性能有重要影响。减少 碳含量并降低非晶态碳含量，同时不能影响其抗热 震性和抗熔渣侵蚀性能, 是改善含碳功能耐火材料 服役功能和寿命的关键 ${ }^{[23,24]}$ 。

\subsection{1 抗氧化、自修复新型抗氧化剂复合体系}

为确保少量的碳发挥作用, 提高低碳材料的防 氧化性能至关重要。材料基质中加入高效抗氧化剂、 优化材料中碳组分的结构形态是改善抗氧化性能,

表 1 纳/微米多孔隔热材料的性能 ${ }^{[42]}$

Table 1 Properties of developed insulation composite material with micro/nano-sized pores ${ }^{[42]}$

\begin{tabular}{|c|c|c|c|c|c|}
\hline & $\begin{array}{l}\text { Developed } \\
\text { composite plate }\end{array}$ & $\begin{array}{l}\text { Developed plate with } \\
\text { nano-sized pores }\end{array}$ & A Company & B Company & $\begin{array}{c}\text { Porextherm plate } \\
\text { with nano-sized pores }\end{array}$ \\
\hline $\begin{array}{l}\text { Thermal conductivity } \\
\left(1000^{\circ} \mathrm{C}\right) /\left(\mathrm{W} \cdot \mathrm{m}^{-1} \cdot \mathrm{K}^{-1}\right)\end{array}$ & 0.087 & 0.063 & $0.050\left(800^{\circ} \mathrm{C}\right)$ & - & 0.062 \\
\hline Bulk density/(g· $\left.\mathrm{cm}^{-3}\right)$ & $0.55-0.65$ & $0.35-0.4$ & $0.30-0.35$ & - & $0.35-0.45$ \\
\hline Service temperature $/{ }^{\circ} \mathrm{C}$ & 1800 & 1100 & 850 & 650 & 1100 \\
\hline Linear change $/ \%\left(1000^{\circ} \mathrm{C}, 24 \mathrm{~h}\right)$ & $\sim 1.5$ & $<2$ & - & - & $<2$ \\
\hline
\end{tabular}



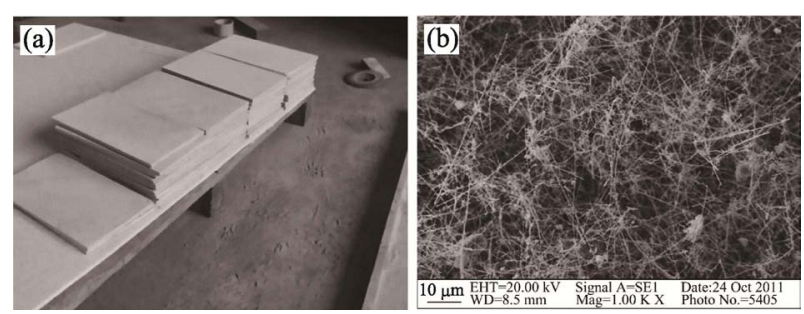

图 3 氮化硅/碳化硅复相多孔陶瓷的产品(a)和 SEM 照片(b) ${ }^{[42]}$ Fig. 3 The product photo and SEM image of porous silicon nitride-silicon carbide composites ${ }^{[42]}$

(a) Product(STIC-n); (b) SEM photograph
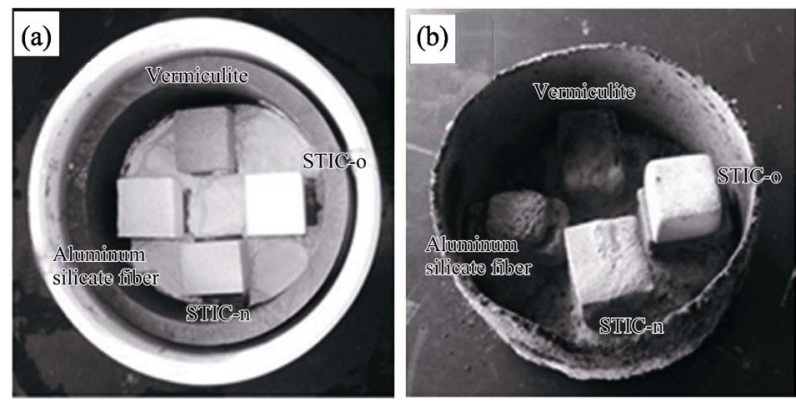

图 4 几种隔热材料侵蚀实验前(a)后(b)外观对比 ${ }^{[43]}$

Fig. 4 Comparison of erosion resistance of several insulation materials (a) before and (b) after test ${ }^{[43]}$

实现功能耐火材料低碳化的有效途径。基于服役环 境下材料的反应热力学和优势区相图, 采用金属 $\mathrm{Al} 、 \mathrm{Si}$ 微细粉, 以及 $\mathrm{Al}-\mathrm{Si}$ 复合微粉等, 通过热处理 或高温服役时原位反应生成的 SiC、AlN 等高抗侵 蚀、高导热物相, 或具有低维结构的 $\mathrm{SiC}$ 晶须等非 氧化物陶瓷相, 获得了碳与高导热高温陶瓷复相结 合的低碳耐火材料, 如图 5 所示, 在碳含量为 $10 \%(w)$ 的低碳 $\mathrm{Al}_{2} \mathrm{O}_{3}-\mathrm{C}$ 材料中添加 $\mathrm{Al}-\mathrm{Si}$ 复合微粉, 热处理 后气孔细化并实现 $\mathrm{SiC}$ 纤维增强, 提高了材料高温 力学性能, 而且气孔的微细化抑制了熔渣渗透, 协 同改善了抗氧化性、抗侵蚀性及抗热震性 ${ }^{[3,44]}$ 。在 $\mathrm{Al}_{2} \mathrm{O}_{3}-\mathrm{C}$ 材料中添加 $\mathrm{Al}_{4} \mathrm{SiC}_{4}$ 合成抗氧化剂 ${ }^{[36]}$, 高温服 役时 $\mathrm{Al}_{4} \mathrm{SiC}_{4}$ 氧化生成 $\mathrm{Al}_{2} \mathrm{O}_{3} 、 \mathrm{SiC}$ 及 $\mathrm{C}$ 的原位反应, 产生的 197.2\%体积膨胀使气孔细化, 抑制了碳氧化 和熔渣渗透，实现材料服役时在线自增强与修复。

\subsection{2 低维石墨化碳在低碳功能耐火材料中的应用}

1) 酚醛树脂催化裂解形成低维石墨化碳结构。 选择合适的 $\mathrm{Fe} 、 \mathrm{Co} 、 \mathrm{Ni}$ 等过渡元素的无机或有机 化合物作为催化剂, 酚醛树脂在裂解过程中产生的 $\mathrm{CO} 、 \mathrm{C}_{2} \mathrm{H}_{2}$ 及 $\mathrm{CH}_{4}$ 等气体在过渡金属催化作用下形 成碳纳米管、纳米碳纤维等低维石墨化碳, 使材料 的高温强度和抗热震性均有所提高。实验研究表明, 选用 $\mathrm{KCl}$ 等作为催化剂可提高催化效应, 提高热处 理时酚醛树脂的残碳率和低维碳纳米管或碳纤维生
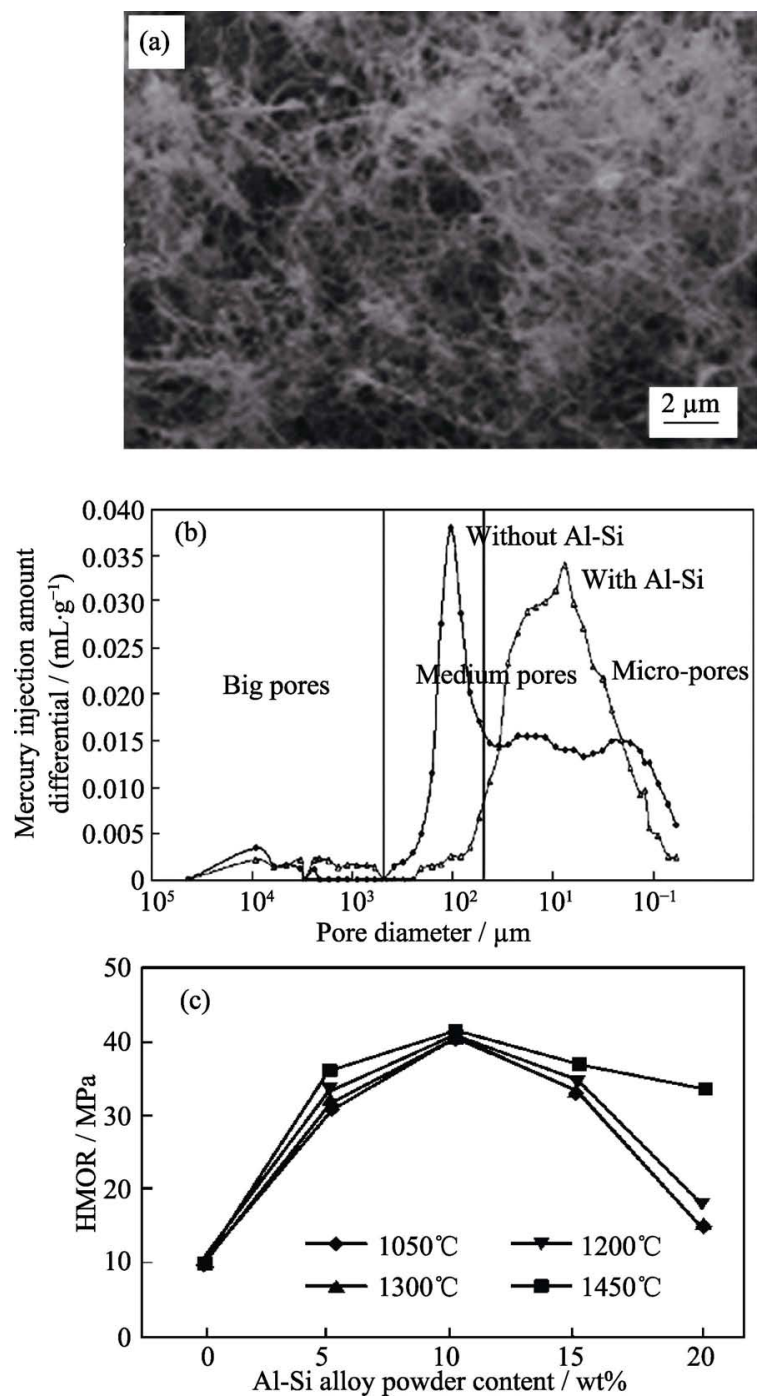

图 $5 \mathrm{Al}-\mathrm{Si}$ 复合粉抗氧化剂对低碳 $\mathrm{Al}_{2} \mathrm{O}_{3}-\mathrm{C}$ 材料微结构和性 能的影响 ${ }^{[44]}$

Fig. 5 The influence of Al-Si alloy antioxidant additives on the microstructure and properties of $\mathrm{Al}_{2} \mathrm{O}_{3}-\mathrm{C}$ refractories ${ }^{[44]}$

(a) Fibrous substance formed by antioxidant reaction; (b) Narrowing influence on the pores distribution; (c) Effect on HMOR

成量, 从而改善了树脂结合碳的脆性和强度 ${ }^{[45]}$, 减 少碳在钢液中的溶解。图 6 为 $\mathrm{KCl}$ 催化剂对树脂热 解残碳率的影响和生成低维碳的形貌。

2) 氧化膨胀石墨制备低维纳米石墨-氧化物复 合粉体。石墨的微细化是发展低碳化功能耐火材料 的重要途径。相对于鳞片石墨, 片层结构的膨胀石 墨具有孔隙率高、比表面积大、活性高以及高压缩 率和高弹性率等特点。采用高能球磨将膨胀石墨和 微米氧化铝粉体混合研磨, 获得纳米碳包覆氧化铝 复合粉体 ${ }^{[4]}$, 如图 7 所示, 不仅获得纳米级石墨, 而 且解决了纳米碳难以均匀分散的技术难题。高度分 散的低维石墨化碳提高了材料的抗高温熔渣侵蚀性, 同时发挥了纳米碳能量耗散、应力吸收等作用, 弥 

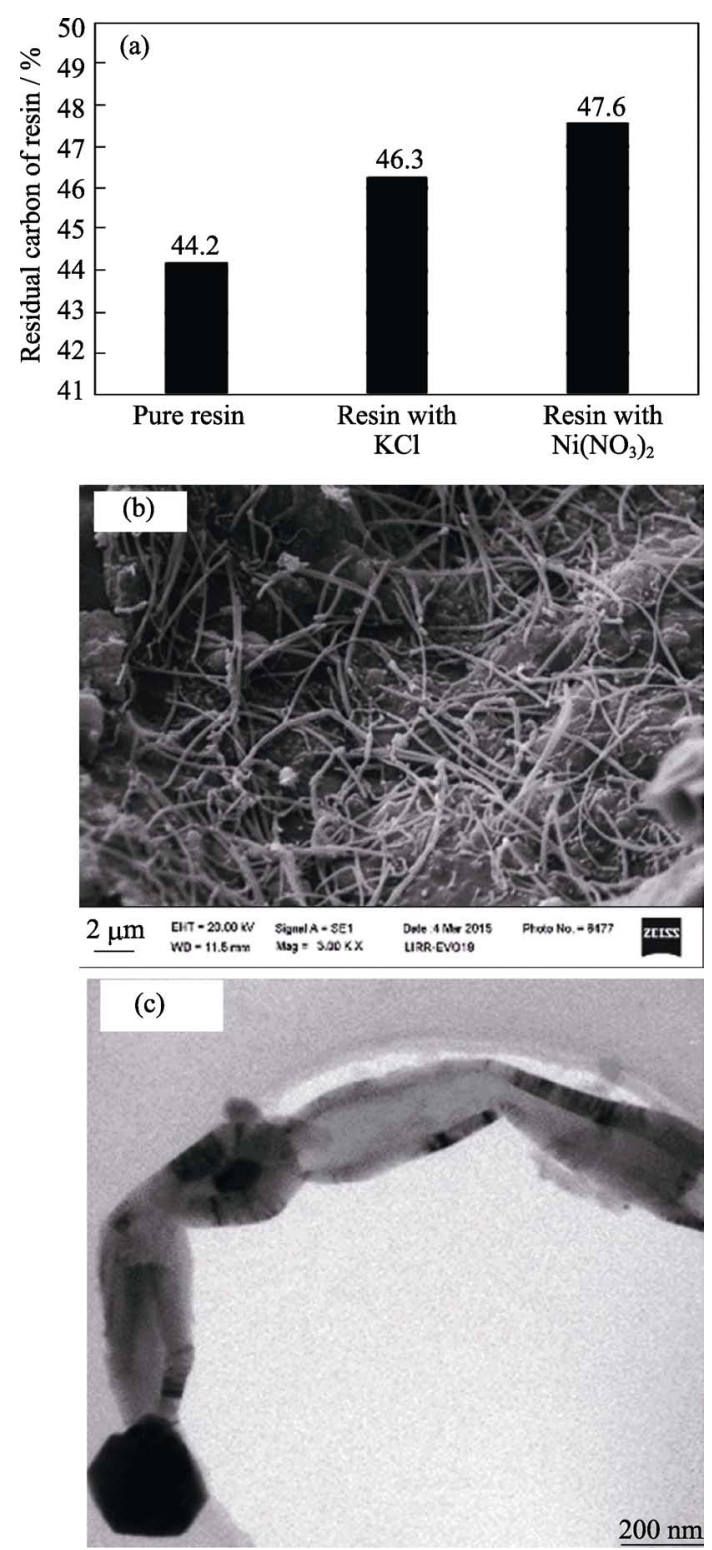

图 6 (a)不同催化树脂的残碳率, (b)裂解生成的纤维碳 SEM 照片和(c)纤维碳 TEM 照片 ${ }^{[45]}$

Fig. 6 (a) Char yield of phenolic resins, (b) SEM image of carbon fiber and (c)TEM image of carbon fiber ${ }^{[45]}$

补碳减少对材料热物理、机械性能及抗热震性能的 不利影响, 从而使低碳材料兼有较好的抗热震性和
抗侵蚀性。

\section{3 功能耐火材料低热应力化设计}

采用数值模拟分析高温服役环境下不同复合材 料在经受钢液热冲击时的温度场和应力场响应等, 发现不同气孔率与微结构、不同热导率与热膨胀系 数的材料以不同形式多层复合，其温度场随时间响 应不同，相应的造成热应力在材料中分布的差异 ${ }^{[5]}$ 。 基于材料服役微环境的不同对其进行功能分区，通 过不同材料的设计可显著优化通钢瞬间其内部的温 度场分布, 大幅度降低最大热应力; 同时多层复合 改变了应力应变关系及应力在材料中的分布, 从而 提高材料的抗热震性能。

采用 $\mathrm{Al}_{2} \mathrm{O}_{3}$-C 复合材料制备的长水口，服役时 瞬间经受从室温到 $1650^{\circ} \mathrm{C}$ 以上钢液的强烈热冲击, 产生的热应力易造成水口断裂。基于功能分区，设 计了碳含量不同的梯度多层复合材料(如图 8 所示): 与钢液接触的内层材料采用 $3 \sim 5 \mathrm{~mm}$ 厚的高气孔率 (23\%)、低热导率的低碳 $(w(C)=1 \%$ 3\%)材料, 不仅 可减少钢液的增碳，而且使通钢瞬间产生的最大温 度梯度发生于该层材料, 该层的高气孔率多孔结构 可缓释应力集中，从而大幅降低受热冲击时最大热 应力 (见图 9); 在受高温钢液冲蚀或熔渣侵蚀严重 的部位, 采用气孔率为 $13 \%$ 、显微结构优化的含碳 $(w(\mathrm{C})=6 \%$ 24\%)材料，材料蚀损速率下降 30\%以上; 本体采用气孔率为 $15 \%$ 的高碳 $(w(C)=26 \%$ 32\%)材 料, 赋予材料足够强度保证长水口的结构功能。梯 度多层复合设计实现了材料抗热震性与抗侵蚀性及 功能性的协同提升。

\section{4 结语}

随着高温工业的发展, 耐火材料承担起更多的 功能。由于耐火材料是多相、多尺度复杂结构的复 合材料，其服役环境多样和复杂，以组成、结构、性 能与功能等服役行为一体设计为核心, 发展以长寿
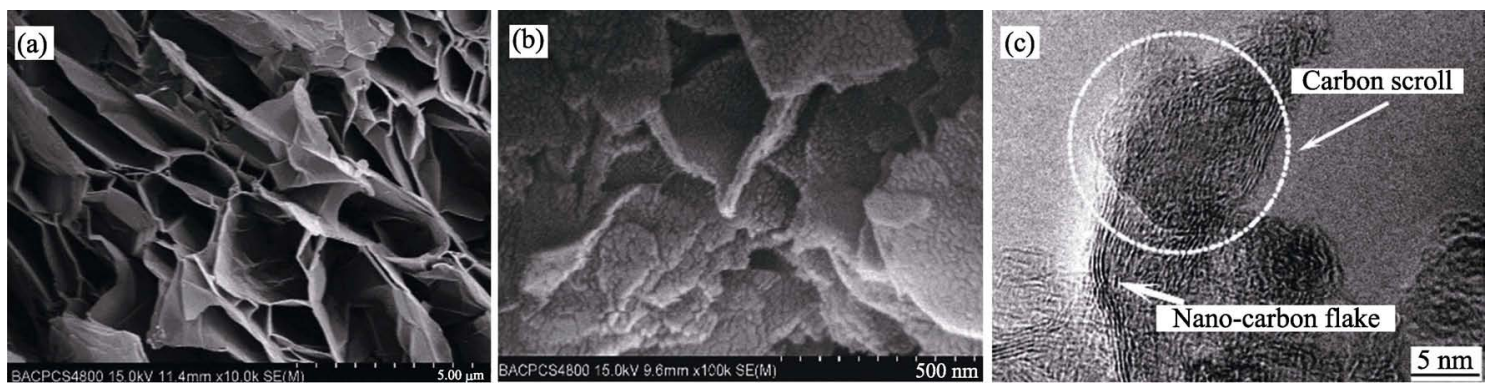

图 7 (a)膨胀石墨的 SEM 照片, (b)纳米碳包覆氧化铝复合粉体的 SEM 照片和(c)形成的纳米碳的 TEM 照片 ${ }^{[4]}$

Fig. 7 (a) SEM image of expanded graphite, (b) SEM image of alumina composite powder covered by nano-carbon and (c) TEM image of nano-carbon ${ }^{[4]}$ 


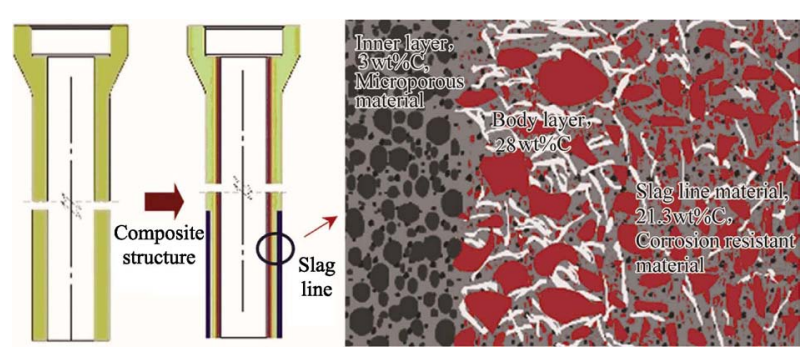

图 8 长水口功能分区示意图 ${ }^{[42]}$

Fig. 8 Schematic diagram of the long nozzle with composite structure ${ }^{[42]}$
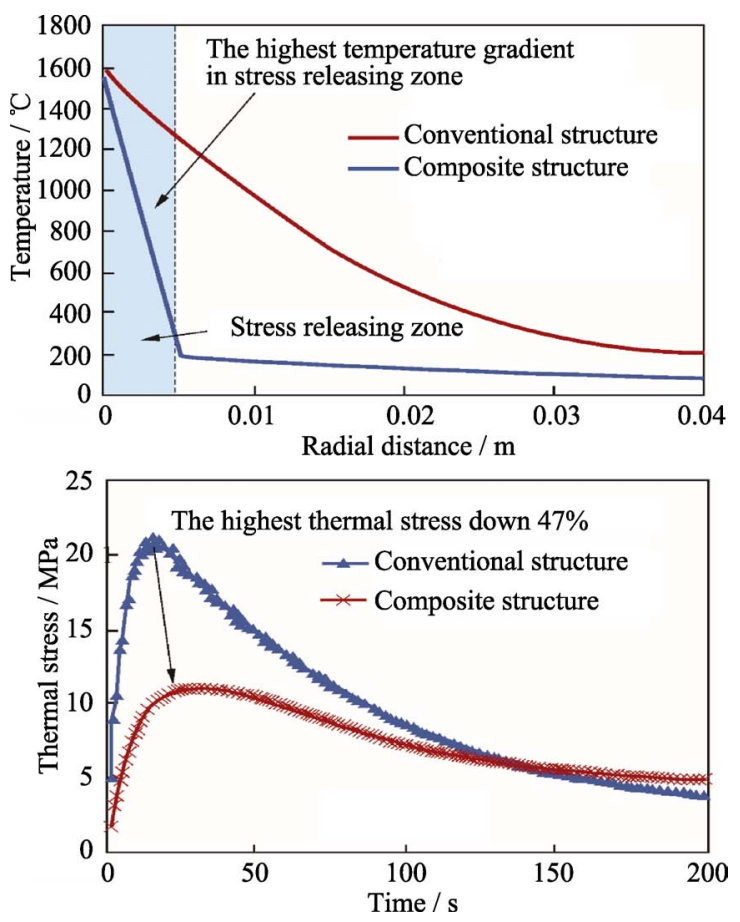

图 9 应力缓释区对温度场和最大热应力的影响 ${ }^{[42]}$

Fig. 9 Effects of stress buffer release area with micro-porous structure on temperature field and maximum thermal stress ${ }^{[42]}$

化、功能化、轻量化、部件化和生态化为特征的先 进耐火材料是耐火材料发展的方向。

结合先进陶瓷的制备技术，实现了高温隔热性 能及其他服役性能的微结构精细化调控, 开发出低 导热率、长寿命、耐高温新型纳米隔热材料, 以及 耐高温、高抗侵蚀性的非氧化物复合隔热耐火材料。

以优化高温服役行为为核心，数值模拟技术和 高温模拟实验相结合, 采用耐火材料结构功能一体 化设计, 突出服役功能化的结构设计与材料的优化 配置, 实现服役长寿化和功能化, 满足了高品质钢 高效生产的需要。

耐火材料的功能化和轻量化设计可从宏观结构 复合及骨料颗粒、基质及气孔三相的微观结构设计 与调控着手, 融合先进陶瓷的成型和制备技术等, 获得梯度或多层复合结构, 拓展了材料性能调控的
空间，实现特定关键服役性能和功能的协同优化提 升, 从而达到减量化、功能化或改善抗高温熔体侵 蚀性能延长使用寿命等目的。

\section{参考文献:}

[1] 李红霞. 高温工业的发展与耐火材料的技术进步. 耐火材料, 2006, 40(增刊): 4-8.

[2] 陈肇友, 李红霞. 镁资源的综合利用及镁质耐火材料的发展. 耐火材料, 2005, 39(1): 6-15.

[3] LI H X, LIU G Q. Current situation and development of refractories for clean steel production. China's Refractories, 2013, 22(3): $1-6$.

[4] 吴小贤, 李红霞, 刘国齐, 等. 高能球磨合成纳米碳包覆 $\alpha$-Al2O3 复合粉体. 无机材料学报, 2013, 28(3): 261-266.

[5] 刘辉敏, 李红霞, 洪彦若, 等. 复合结构长水口热应力有限元分 析. 硅酸盐学报, 2009, 31(12): 2000-2006.

[6] SONG Y Y, LIU G Q, LI H X, et al. Influence of ladle purging plug airway on flow properties of liquid steel. Advanced Materials Research, 2012, 472-475: 2581-2587.

[7] LI H X, YANG B, LIU G Q, et al. Gradient Functional Refractories for High Efficient Con-casting (invited). Proceedings of the 6th International Congress on the Science and Technology of Steelmaking(I), Beijing, China, 2015: 4-8.

[8] 张洪哲, 李富朝, 孙庚辰, 等. 高风温长寿热风炉用高效小孔径 格子砖的设计及选材. 耐火材料, 2015, 49(5): 376-380.

[9] 王佳平, 金广湘, 王勇峰, 等. 新型复相氮化物结合碳化硅耐火 材料在干熄炉斜道区的应用和分析. 西安：2016 年(第十届)焦 化节能环保及干熄焦技术研讨会论文集, 2016: 96-101.

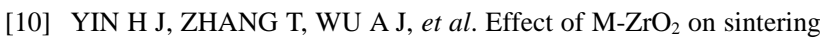
behavior and thermal shock resistance of dense $\mathrm{Cr}_{2} \mathrm{O}_{3}$ material. Advanced Materials Research, 2011, 199-200: 1928-1931.

[11] 孙红刚, 陈 杰, 范志辉, 等. 新型高铬砖在 GE 气化炉的试用 研究. 大氮肥, 2011, 34(增刊 2): 108-111.

[12] 耿可明, 王金相. $\mathrm{Cr}_{2} \mathrm{O}_{3}$ 在水煤浆气化炉过程中的行为. 耐火材 料, 2015, 49(1): 68-71.

[13] 李红霞, 王金相. 水泥窑用碱性耐火材料无铬化的技术进展. 中国水泥, 2004, 10: 79-82.

[14] LI H X, LIU J, FENG H X, et al. Development and application of chrome-free refractory materials for RH degasser. China's Refractories, 2014, 23(4): 1-5, 12.

[15] GE H B, WANG G, YUAN B, et al. Fabrication and microstructure of porous $\mathrm{SiC}$ ceramics using suspension emulsions as pore-forming agents. Ceramics International, 2014, 40(8): 11705-11711.

[16] WU H B, HUANG Z R, WANG G, et al. Alumina heat insulator through composite poring mechanisms. International Journal of Applied Ceramic Technology, 2015, 11(6): 1061-1067.

[17] 徐殿利. 2016年全国耐火材料行业生产运行情况及 2017 年耐火 材料市场预测分析. 北京: 2017 年耐火材料行业协会年会报告 会, 2017: 1-8.

[18] 江东亮, 袁渭康, 钱 锋, 等. 我国高耗能工业高温热工装备节 能科技发展战略研究. 北京: 科学出版社, 2017: 50-55.

[19] 李红霞, 杨 涁. 中国石墨资源和产业状况概述. 郑州: 耐火原 料学术交流会论文集, 2011: 1-11.

[20] 刘俊光, 魏同. 我国耐火材料工业节能降耗技术及发展方向. 太原：新形势下全国耐火原料发展战略研讨会论文集，2014: 193-194.

[21] HEMRICK J G, HAYDE H W, ANGELINI, et al. Refractories for industrial processing: opportunities for improved energy efficiency. Industrial Technologies Program, 2005, 1: 4-6. 
[22] HEMRICK J G. Improved refractories=energy saving. American Ceramic Society Bulletin, 2013, 92(7): 32-35.

[23] HEADRICK W L. Towards a "greener" future with advanced refractories. American Ceramic Society Bulletin, 2013, 92(7): 28-31.

[24] SEMLER C E. Refractories-the world most important but least known products. American Ceramic Society Bulletin, 2014, 93(2): 34-39.

[25] GUIRE E D. State raw materials 2013-overview and frontiers. American Ceramic Society Bulletin, 2013, 92(6): 24-28.

[26] CERAME-UNIE. The Ceramic Industry Roadmap. Paving the Way to 2050, 2012, 1: 40-45.

[27] COHEN L. Challenge and opportunities for refractory manufacturers in the UK. Refractories Engineer, 2013, 11: 12-17.

[28] JARVIS D R. An overview of the current 2013 global refractories industry. International Ceramic Review, 2013, 62(4): 262-266.

[29] XU D L, CUI Y S, YANG K, et al. On the future of Chinese cement industry. Cement and Concrete Research, 2015, 78: 2-13.

[30］殷瑞钰. 高效率、低成本洁净钢“制造平台”集成技术及其动态 运行. 钢铁, 2012, 47(1): 1-12.

[31] LI HONGXIA. Development of Refractory Industry in China with Restricts of Resource, Energy and Environment Factors. Proceedings of UNITECR 2011, Kyoto, Japan, 2011: 122-123.

[32] 李红霞. 经济下行时中国耐火材料行业发展的思考. 耐火材料, 2012, 46(5): 321-324.

[33] JAKOBSEN D, GOTSCHEL I, ROOSEN A. Manufacture of multilayer composite with optimized thermal and chemical properties via the tape casting process. Refractories Worldforum, 2016, 8(2):
86-94.

[34] 蔡斌利, 李红霞, 赵世贤, 等. 水煤浆气化炉中 $\mathrm{O}_{2}$ 分压和 $\mathrm{Cr}_{2} \mathrm{O}_{3}$ 稳定性的热力学计算. 耐火材料, 2016, 50(6): 411-415.

[35] YANG W G, LIU G Q, LI H X, et al. Thermal Stress Distribution in Stopper by Finite Element Analysis. Proceedings of UNITECR 2013, Columbia, Canada, 2013: 154-158.

[36] 李红霞. 对耐火材料的性能调控及设计的一些思考. 耐火材料, 2013, 47(增刊 1): 1-2.

[37] SEMLER C E. Review of advances in refractories. International Ceramic Review, 2011, 2: 77-81.

[38] SUGITA K. The past and future of refractories technology. International Ceramic Review, 2012, 1: 8-12.

[39] SEMLER C E. The advancement of refractories technology never stops. Refractories Worldforum, 2014, 6(4): 27-31.

[40] PHILIP A. An introduction to Alkaline Silicate wool products. Proceedings of the Institute of Industrial Engineers Asian Conference 2013, Taipei, 2013: 100-105.

[41] 孙小飞, 王 刚, 袁 波. 高铝纤维复合 $\mathrm{SiO}_{2}$ 质纳米微孔隔热材 料研究. 耐火材料, 2014, 48(6): 406-408.

[42] LI H X. Some design consideration of advanced refractories. Refractories Worldforum, 2017, 9(4): 99-105.

[43] 张 琪. 隔热材料抗冰晶石蒸汽侵蚀机理研究. 洛阳: 中钢集团 洛阳耐火材料研究院硕士学位论文, 2016.

[44] 刘国齐. $\mathrm{Al}_{2} \mathrm{O}_{3}-\mathrm{Al}-\mathrm{C}$ 功能耐火材料的热变化和应用研究. 北京: 北京科技大学博士学位论文, 2006.

[45] 吴小贤. 含纳米碳新型低碳铝碳耐火材料研究. 北京: 北京科 技大学博士学位论文, 2013 .

\section{我与严东生先生}

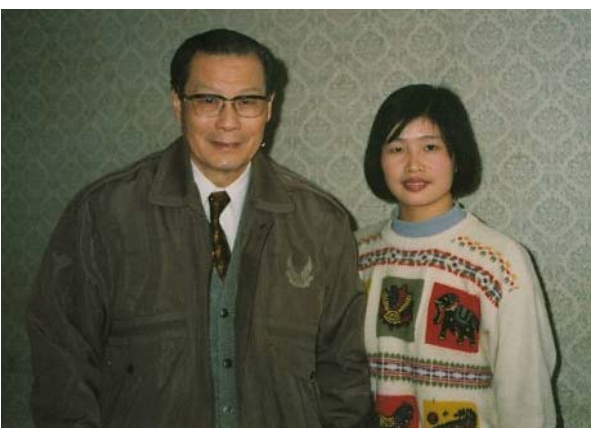

严东生先生是我的博士生导师, 也是我学术研究的领路人。 攻读博士期间, 每季度要向先生作一次系统汇报。每次汇报, 先 生都会认真倾听。他能非常清楚地记得前一次汇报的内容, 耐心 询问工作进展, 准确地指出我工作计划的偏差及存在的问题。先 生的严格要求, 培养了我严谨的治学态度和一丝不苟的工作作风。 在新材料科学研究上, 先生一贯主张不仅需要捕捉和吸纳国际最 新信息和技术, 还要走出国门, 走向世界, 参与国际合作, 才能 在学科领域内站到国际前沿, 高屋建瓴, 领先一步。读博期间, 我作为高级访问学者在美国 Michigan 大学工作, 开拓了视野, 学 习锻炼了能力, 使我其后的科研工作受益匪浅。赴美国留学前, 先生教诲我, 一定要大胆张开口说英语, 不 要怕出错, 第一次出错, 第二次出错, 第三次肯定会说得非常好。上世纪 90 年代初, 科技人员收入普遍不 高, 先生从自己获得的科技奖金中拿出一部分, 设立助学基金, 补贴帮助学生, 激励学生奋发向上, 创新 进取，为国家为社会作出更多的贡献。先生始终坚持 “国家利益为大，个人名利为小” ，教诲我们保持对 国家发展、民族复兴和社会进步的信心。他常说, 立志为中国的建设发展而献身是我国几代科学家的理想 和美德。记得我在日本工作时, 他来信嘱托我好好利用在国外的学习机会, 如果有条件, 可以到美国去继 续学习工作, 开拓思路, 归国后可以更好地为国家作贡献, 报效祖国。每当我遇到困难和挫折, 先生总是 耐心倾听，并给予非常有效的指导。能够有幸成为先生的弟子，是我一辈子的荣耀。先生指导我，默默关注 我, 在战略高度上为我指引方向。“学高为师, 身正为范”。虽然经先生授业仅短短数载, 受益却是终生, 恩师情谊, 终生难忘。 